Review

\title{
The Allure of High Total Angular Momentum Levels in Multiply-Excited Ions
}

\author{
Elmar Träbert $\mathbb{D}$ \\ Astronomisches Institut (AIRUB), Fakultät für Physik und Astronomie, Ruhr-Universität Bochum, \\ D-44780 Bochum, Germany; traebert@astro.rub.de; Tel.: +49-234-322-3451
}

Received: 20 October 2019; Accepted: 12 November 2019; Published: 15 November 2019

check for updates

\begin{abstract}
In the interaction of fast ions with dense matter, the collision frequency is high enough to facilitate the simultaneous excitation of several electrons. Such multiply-excited few-electron systems have been exploited variously for plasma diagnostics. Beam-foil spectroscopic techniques, benefiting from the inherent time-resolution offered by the geometry of typical experiments, have proven particularly fruitful for the study of emission patterns and level lifetimes of specific multiply-excited levels, especially those of maximum spin and total angular momentum. Typical cases are recalled to illustrate some general principles. Among many others, earlier beam-foil measurements have targeted the core-excited $2 p^{5} 3 s 3 p{ }^{4} D_{7 / 2}-2 p^{5} 3 s 3 d^{4} F_{9 / 2}$ transition in several Na-like spectra ranging from $\mathrm{S}$ VI to $\mathrm{Cu}$ XIX. Data on the six intermediate elements missing at that time are now added. The interest in such atomic systems with multiple excitations and high total angular momentum values is discussed with a variety of examples.
\end{abstract}

Keywords: atomic spectroscopy; isoelectronic sequences; computations

PACS: 32.30.Jc; 32.70.Cs; 31.15.-p

\section{Introduction}

In his 1964 Handbook of Physics article on atomic spectra [1], B. Edlén mostly treated the excitation of a single valence electron. This field is not exhausted yet more than half a century later. However, the simultaneous excitation of several electrons can also happen. While this is rare in conventional light sources, it happens frequently by collisions in dense plasmas, including the interaction of a fast ion beam with solid (foil, surface) targets, in high-power laser produced plasmas, or by inner-shell ionization processes as can be affected by photons in astrophysical plasmas or by X-ray lasers in the laboratory. Out of the vast multitude of atomic cases to study, I am selecting a small group to discuss some developments that I have witnessed or participated in. These are levels with a high value of the total angular momentum $J$, which have a somewhat limited number of decay channels, each of which therefore may be more prominent and thus better detectable than the many weak decay channels of other levels. The same general feature is, of course, found in singly excited atomic systems of which the structure is often simpler. The inclusion of such high-J levels in computations requires the inclusion of all lower $n$ - and J-levels, which in earlier days might have amounted to a major challenge. A challenge remains the fact that there usually are numerous levels of non-maximum $J$, often of different multiplicity (total spin $S$ ). All levels of the same parity and $J$ value interact with each other, and this complexity limits the accuracy in the computation of individual levels. Here, the maximum- $J$ levels are easier to obtain accurately because, in many cases, they are the only ones in their shell and thus much less affected by mixing.

The review below discusses some cases of core-excited few-electron ions in which the pursuit has encountered difficulties and limitations in isoelectronic studies, and other cases with multiple 
excitation in outer shells (such as in Na-like ions) for which a decent theoretical systematic analysis was achieved 30 years ago but with only a patchy data record. However, some of the gaps can be filled by now. It may be useful to keep such measurement situations in mind so that the databases can be augmented and specific analyses can be improved.

\section{General Remarks and Earlier Work}

Doubly excited or core-excited atoms are those that have several electrons not in their ground state or of which the level series do not converge to the ground state of the next more highly charged ion but to one of its excited levels. In the 1940s, T.-Y. Wu [2] recognized the emission from doubly excited He atoms. Around the same time, negative ions of He were found, which apparently feature at least one rather long-lived excited level. In such three-electron ions $\left(\mathrm{He}^{-}\right.$and $\left.\mathrm{Li}^{0}\right), \mathrm{J} . \mathrm{R}$. Pietenpol [3] suggested metastability against autoionization to occur for the $1 \mathrm{~s} 2 \mathrm{~s} 2 \mathrm{p}{ }^{4} \mathrm{P}_{5 / 2}^{\mathrm{o}}$ level. In fact, he incurred that, among the usual effects that enable the mixing with autoionizing levels in the (doublet) continuum, Coulomb, spin-orbit, and spin-other-orbit matrix elements vanish and that only the magnetic spin-spin interaction permits autoionization to happen. The microsecond-lifetime of this $\mathrm{He}^{-}$level even has a technical application: ion accelerators exploiting the tandem principle require negative ions to start with. The lifetime of this particular level of the $\mathrm{He}^{-}$ion is sufficiently long to extract ions from the ion source and to accelerate them to the (positively charged) high voltage terminal of the machine. There, the ions pass through a stripper medium and lose electrons, thus becoming positive ions that continue being accelerated towards ground potential. Hence, intensive beams of $\alpha$ particles $\left(\mathrm{He}^{2+}\right.$ ions) are available from tandem accelerators that otherwise cannot provide rare gas ion beams. Moreover, negative hydrogen ions $\left(\mathrm{H}^{-}\right)$play a significant role in the shape of the visible spectrum of the sun (and of other stars, of course) while negative ions of deuterium are the starting point for neutral beam heating in large plasma experiments for fusion research, such as ITER. Negative ions of many elements have been observed and their properties computed. They are a challenge for atomic structure theory because the extra electron is bound to the neutral parent atom only because of electron-electron interactions. However, negative ions provide a rich field for research of their own beyond the present treatise.

\subsection{Satellites to Diagram Lines in He-Like Ion Spectra}

The same atomic features that interest some physicists are possibly underappreciated by others and vice versa. An example is the satellite lines $1 s^{2} 2 \ell-1 \mathrm{~s} 2 \ell 2 \ell^{\prime}$ (involving core-excited Li-like ions) to the $1 s^{2}-1 s 2 \ell$ diagram transitions in He-like ions. A.H. Gabriel [4] discussed the plasma diagnostic potential of the satellite lines, and in that course, he suggested an alphabetic shorthand notation for the lines. He chose $w, x, y$, and $z$ as names for the primary $n=1$ to $n=2$ resonance and intercombination lines in the spectra of two-electron ions and $a$ to $v$ for the associated (X-ray) satellite lines in the spectra of three-electron ions. At a first glance, the discussion and alphabet-filling listings of 26 transitions in total look exhaustive. However, what is left out is the $1 \mathrm{~s} 2 \mathrm{~s} 2 \mathrm{p}^{4} \mathrm{P}_{5 / 2}^{\mathrm{o}}$ level because its decay rate is much lower than those of the other satellite transitions. Gabriel evidently judged the magnetic quadrupole (M2) transition to the $1 s^{2} 2 s^{2} S_{1 / 2}$ ground level to be of little interest to plasma physics. A contrasting aspect arises from a different type of spectroscopy, using fast ion beams that pass through a thin foil inside of which the electrons provide a dense (solid state density, $n \approx 10^{24}$ electrons $/ \mathrm{cm}^{-3}$ ) plasma. The fast ions emerge into a high vacuum (pressure $p \approx 10^{-6}$ mbar) at a very low particle density $\left(n \approx 10^{11}\right.$ atoms $/ \mathrm{cm}^{-3}$ ) and can be studied practically free of interactions [5-10]. The many satellite lines of the three-electron system fall into a narrow wavelength interval and require high spectral resolution for meaningful studies [11-13]. The beam-foil light source, however, suffers from significant Doppler broadening, and therefore, an experimenter struggles to resolve such satellite spectra near the diagram (resonance) lines of two-electron ions. Nevertheless, the technique offers another boon: by a simple mechanical shift of the exciter foil, it facilitates the recording of time-resolved spectra and thus the measurement of atomic lifetimes in the nano- to picosecond 
ranges [14]. Similarly, in the study of Auger electrons (from the autoionization of multiply excited few-electron ions) [15,16], "delayed" spectra (relatively) enhance the decay signal of longer-lived levels [17]. Following the example of S. Mannervik [13] (an article recommended for a review of techniques and problems not covered in the present text), I concentrate my report on photon transitions, many of which compete with Auger decays. Most of the doubly excited three-electron levels are very short-lived, but one of them stands out in slightly "delayed" satellite spectra and thus yields access to a "forbidden" decay mode [18]. That level is the very $1 \mathrm{~s} 2 \mathrm{~s} 2 \mathrm{p}{ }^{4} \mathrm{P}_{5 / 2}^{\mathrm{o}}$ level which in Gabriel's treatise and tables is not even mentioned, but which has since been studied for a number of elements for the isoelectronic Z-scaling of the M2 transition rate. It has taken decades until, eventually, the same transition was recognized also in the X-ray spectrum of a low-density plasma discharge [19].

Among the multitude of core-excited $1 \mathrm{~s} 2 \ell 2 \ell^{\prime}$ levels in three-electron systems, the $1 \mathrm{~s} 2 \mathrm{~s} 2 \mathrm{p}{ }^{4} \mathrm{P}_{J}^{\mathrm{o}}$ and $1 \mathrm{~s} 2 \mathrm{p}^{2}{ }^{4} \mathrm{P}_{J}$ levels are of particular interest also because of the ultraviolet (UV) transitions between these terms. The levels of the upper multiplet have three competing decay modes: intra-shell electric dipole transitions in the ultraviolet, inter-shell higher-multipole order X-ray transitions to the low-lying doublet levels, and autoionization. At low nuclear charge $Z$, the transition rates of the decay branches differ clearly and they scale differently with increasing Z. At low Z, the UV decay (the rate of which increases linearly with $Z$ ) dominates. The various mechanisms that permit autoionization are weak at low $Z$, but they scale with $Z^{3}$ to $Z^{4}$ and therefore gain importance along the isoelectronic sequence. The higher-multipole order $X$-ray transition rates scale the steepest with $Z$ and, thus, they dominate at high $Z$. Atomic lifetime measurements along the isoelectronic sequence can track the individual contributions to the total decay rate $[20,21]$. The measurements are most easily done on the UV decay branch because, there, the spectral resolution is good enough to resolve decays of individual fine structure levels [22-24]. However, the fluorescence yield of the UV branch decreases when the competing decay modes increase and eventually dominate. Work by H.M. Hellmann et al. at Bochum [23] has covered $\mathrm{Mg}^{9+}$ and $\mathrm{Al}^{10+}$; the highest- $Z$ data published apparently are those on $\mathrm{Si}^{11+}$ obtained by J.P. Buchet et al. at Lyon (France) [25].

So far, our examples have mentioned singly and doubly excited three-electron systems. However, all three electrons may be not in their ground state, and arguably, the most peculiar excitation level there is the triply excited $2 \mathrm{p}^{3}{ }^{4} \mathrm{~S}_{3 / 2}^{\mathrm{o}}$ level with its notable longevity, which has been demonstrated in beam-foil spectra by Mannervik et al. [26] (see this paper also for references to earlier work, with theoretical concepts appearing already in the 1940s, and to the excellent theoretical studies by K.T. Chung and colleagues). The extreme ultraviolet (EUV) decay of this level has been searched for in elements from $\mathrm{He}(Z=2)$ up to $Z=6$ by now $[27,28]$. While in spectroscopy such levels and their decays may initially have appeared to be rather exotic (not to say useless) cases of little general interest, the quest for X-ray lasers in the 1980s and the upcoming interest in hollow atoms in the 1990s (produced, for example, by the interaction of highly charged ions with metallic surfaces [29]) have catalysed a much wider interest. Since then, synchrotron radiation and X-ray lasers have been applied to photoionize neutral atoms by the removal of one or more inner electrons, and atomic systems of multiple excitations equivalent to those produced before by fast ion-foil interaction are the result. Similarly, beyond the early pioneering use of satellite lines for plasma diagnostics, plasma physics has progressed to higher power density plasmas, finding more and more seemingly "nonstandard" satellite lines (see, for example, the work by F.B. Rosmej et al. [30]). Again, some of these lines had been seen in beam-foil spectroscopy decades earlier [31-34] but without a comprehensive theoretical treatment available at the time.

Such multi-electron systems with multiple excitations challenge the capabilities of atomic structure computations. A related testing ground is the study of negative ions, which rely on electron-electron interactions to keep the "surplus" electron bound. Besides the question of the binding (dissociation) energy, there is the question of whether excited states exist and whether transitions between bound states of the negative ion occur. For many negative ions, no excited state has been found, and one might suspect that, if transitions were happening, they should be very weak and thus hard to recognize. 
However, in the spectrum of fast $\mathrm{Li}$ ions after passage through a thin foil, a rather bright line defied identification for years until in 1980 theory [35] and experiment (among others [36]) concluded that the spectral line originated from a negative ion, $\mathrm{Li}^{-}$, and thus represented a transition that involved a triply excited (core-excited) four-electron ion. Moreover, the strong transition seen is not a ground-state transition but one that takes place between two core-excited levels, in this case, $1 \mathrm{~s} 2 \mathrm{p}^{3}{ }^{5} \mathrm{~S}_{2}^{\mathrm{o}}$ and $1 \mathrm{~s} 2 \mathrm{~s} 2 \mathrm{p}^{2}$ ${ }^{5} \mathrm{P}_{1}$ (for more detailed studies and references, see Reference [37]).

The same transition between the lowest quintet levels has been followed experimentally up to Ne VII at Argonne (IL, USA) [38]. A search for the corresponding transitions in $\mathrm{Mg} \mathrm{IX}\left(\mathrm{Mg}^{8+}\right)$ at the Bochum Dynamitron tandem accelerator laboratory (DTL) in 1986 yielded no more than weak indications of (possibly) the lines of interest. The spectra were recorded with a grazing incidence spectrometer, which is not particularly well suited for observations in the long-wavelength part of the EUV spectral range [39]. The candidate spectral features seen were not far in wavelength from computational predictions by T. Brage and C. Froese Fischer [40], but not in agreement with the computations of K.T. Chung [41].

There are many such core-excited atomic systems, with numerous experimental studies aiming at the detections of electrons after autoionization or auto-detachment. On the theory side, see, for example, also the studies by J. Hata and I. P. Grant [42], by K.T. Chung and B. F. Davis (mostly on three-electron ions) [43-46], the work by the group of C.A. Nicolaides (for example, Reference [47]), by N. Vaeck and her colleagues, and by J.H. Blanke (on three- to five-electron ions) [48-51] for computations and further literature references on core-excited levels. These theoretical studies apply a wide variety of computational approaches to atomic structure, from nonrelativistic to fully relativistic, from configuration interaction to many-body perturbation theory, R-matrix, saddle-point, and complex rotation. Several of the program packages can switch between major computational options, and it is not good enough to just name the program package without detailed specifications to tell what has been done. This experimenter's qualification is insufficient to pay justice to the plethora of basics and details involved. However, a recent policy decision by the journal Physical Review A requests that every theory treatment involves an intrinsic check of validity and accuracy. It is, of course, not good enough to claim agreement of one's result with other computations or to state the number of decimals as proof of reliability. A realistic quality assessment is as essential in computational theory as is the error budget in experiment. As highly regarded theoreticians have stated, "if theory and experiment disagree, work on theory; if they agree, improve on the experiment".

\subsection{High-J Levels in Li-Like Ions with $n>2: 1 s 2 p 3 d^{4} F_{9 / 2}^{o}$}

M. H. Chen and B. Crasemann [52] have noted that the $1 \mathrm{~s} 2 \mathrm{p} 3 \mathrm{~d}{ }^{4} \mathrm{~F}_{9 / 2}^{o}$ fine structure level in Li-like ions is peculiar because of its various decay channels of different multipole order, all with their own Z-dependence of the decay rate. Their multi-configuration Dirac-Fock (MCDF) computations yield an autoionization rate (mediated by the Breit interaction, proportional to $Z^{4.6}$ ), electric dipole (E1) transition rates for the EUV transitions $2 \mathrm{~s}-2 \mathrm{p}_{3 / 2}$ (proportional to $Z^{2.8}$ ) and $3 p-3 d$ (in the UV spectral range, with the weakest $Z$-dependence), the electric quadrupole (E2) transition rate for the XUV transition $2 \mathrm{~s}-3 \mathrm{~d}_{5 / 2}$ (proportional to $Z^{6.5}$ ), and the magnetic quadrupole $(M 2)$ transition rate for the $X$-ray transition $1 \mathrm{~s}-2 \mathrm{p}_{3 / 2}$. The spectral ranges indicated in that paper are for elements in the range of $Z$ from about 10 to 20 . The lifetimes $\tau$ of the levels $J=3 / 2,5 / 2$, and $7 / 2$ decrease rapidly (and rather similarly) with increasing atomic number $Z$ from $\tau \approx 1 \mathrm{~ns}$ at $Z=8$ to $\tau \approx 10 \mathrm{ps}$ near $Z=13$, whereas the $J=9 / 2$ level has a much longer lifetime of $\tau \approx 7 \mathrm{~ns}$ at $Z=8$ and $\tau \approx 1 \mathrm{~ns}$ at $Z=15$. The same (and related) levels are of interest in low-energy collisions with charge exchange (CX) reactions. Experiments in France (for example, by the groups at Lyon [53] and Caen), Greece (see, for example, the group at Heraklion [54]), the USA (for example, by the group at Manhattan (KS, USA) [55]), and many others have exploited the presence of long-lived (metastable) excited levels with their often very large cross sections. Closely related to the $1 \mathrm{~s} 2 \mathrm{p} 3 \mathrm{~d}^{4} \mathrm{~F}^{\mathrm{o}}$ term in the three-electron system is the $2 \mathrm{~s} 2 \mathrm{p} 3 \mathrm{~d}^{4} \mathrm{~F}^{\mathrm{o}}$ term in boron-like ions, as treated computationally by G. Miecznik and T. Brage [56]. 
The case of the $1 \mathrm{~s} 2 \mathrm{p} 3 \mathrm{~d}{ }^{4} \mathrm{~F}_{9 / 2}^{\mathrm{o}}$ fine structure level should be easily measurable in principle by beam-foil spectroscopic techniques [14] - so, why has it not? Let us look at the $\mathrm{Si}^{11+}$ ion as an example. Silicon ion beams ( $\mathrm{P}$ or $\mathrm{S}$ would do as well) have been produced at various accelerator laboratories and certainly are strong enough to yield sufficient signal even on branched decays. According to Chen and Crasemann's computations, the $2 \mathrm{~s}-3 \mathrm{~d}, 2 \mathrm{~s}-2 \mathrm{p}$, and $3 \mathrm{p}-3 \mathrm{~d}$ transitions are the strongest decay branches with transition rates within a factor of two of each other. The predicted wavelengths are $3.78 \mathrm{~nm}$, $82.9 \mathrm{~nm}$, and $282 \mathrm{~nm}$, respectively, calling for at least two different spectrometers (a grazing incidence spectrometer at the short-wavelength end of operability and a normal-incidence spectrometer) with at least two different detectors (for example, a channeltron or microchannel plate or a charge-coupled device (CCD) camera working in the soft-X-ray range and EUV range and a solar-blind photomultiplier for the UV range). For each of the observation cases, a single spectral line needs to be found that should be distinguishable from the probably also present but less interesting other lines by its longevity. In practice, there usually are many other lines to be seen in spectra recorded close to the exciter foil, among which one hopes to identify lines that can serve for wavelength calibration. The line of interest, however, can become relatively prominent only some distance downbeam of the exciter foil, where it loses intensity more slowly than the others and then shows as a survivor. Most probably, this survivor appears without calibration lines nearby because, in beam-foil spectroscopy, the ion beam is isotopically pure: there will be ions of several charge states but all from only one element/isotope. Incidentally, there are no measures yet of the computational accuracy of the procedure applied by Chen and Crasemann. In each of the three spectral ranges involved, the experiment will need to be able to cover a certain wavelength range and record spectra at a set of distances from the exciter foil (delays after excitation). An optical experiment, preferably with a position-sensitive detector that offers spectral coverage of a certain wavelength range $[57,58]$, could shed much more light on the matter, indeed.

The necessary ingredients for measurements of the three major decay branches of the 1s2p3d ${ }^{4} \mathrm{~F}_{9 / 2}^{\mathrm{o}}$ fine structure level in Li-like ions of $\mathrm{Si}, \mathrm{P}$, or $\mathrm{S}$ have been available in several laboratories several decades ago-but not all in the same laboratory. At Lund (Sweden), spectrometers for all three spectral ranges had been deployed on ion beams, but the Lund Pelletron accelerator was not powerful enough to produce sufficiently highly charged ions. The Lund group of I. Martinson frequently collaborated with the group of P.H. Heckmann at Bochum (Germany), $750 \mathrm{~km}$ southwest of Lund. The Bochum Dynamitron accelerator was able to provide ions of the right energy and high beam current. However, the Bochum group owned grazing-incidence scanning monochromators that served excellently in the EUV but that were barely sufficient in terms of spectral resolving power in the soft-X-ray range. One of the instruments reached the long-wavelength part of the EUV range but was somewhat too slow to be practical there. A suitable normal-incidence monochromator was eventually built by the group of H.H. Bukow at the same institute, but it was used for dedicated work at a much smaller accelerator in the same laboratory only. Nowadays, there are few, but some, accelerator laboratories left that could provide a suitable combination of ion beam production and beam-foil spectroscopic equipment for studying this particular problem.

\subsection{Al-Like Ions: The $3 s 3 p 3 d^{4} F_{9 / 2}^{o}$ Level}

A fair number of computations have addressed Al-like ions, that is, ions with a closed $n=2$ shell and three electrons in the $n=3$ valence shell. Early studies stated that the physics community had interest in only those transitions that connect to the ground configuration and that the $3 \mathrm{~s} 3 \mathrm{p} 3 \mathrm{~d}$ configuration was thus left out. This argument surely reflected the limitations of computer resources at the time. Later on, the $3 \mathrm{~s} 3 \mathrm{p} 3 \mathrm{~d}$ configuration and even the ${ }^{4} \mathrm{~F}^{\mathrm{O}}$ term were eventually included in atomic structure computations, but the highest- $J$ level, $J=9 / 2$, was still left out. With the inner shells filled, the $3 \mathrm{~s} 3 \mathrm{p} 3 \mathrm{~d}{ }^{4} \mathrm{~F}_{J}^{\mathrm{o}}$ levels are fully bound and cannot autoionize, but nevertheless, the lifetimes of the fine structure levels differ because of relativistic effects and some differences in the decay paths. While the lifetimes of the $J=3 / 2,5 / 2$, and $7 / 2$ levels differ slightly from each other (in the range of ns for 
Fe XIV), the $J=9 / 2$ level lifetime is much longer (in the range of several ms for Fe XIV) because the only $J=7 / 2$ level lower in energy is another fine structure level of the same term and not any $E 1$, but only an M1 decay of low transition energy is permitted.

S.S. Churilov and V.E. Levashov [59] have studied laser-produced plasmas and observed decays from higher $n=3$ levels to the $3 \mathrm{~s} 3 \mathrm{p} 3 \mathrm{~d}^{4} \mathrm{~F}^{\mathrm{o}}$ term. Practically concurrently, decays of the $3 \mathrm{~s} 3 \mathrm{p} 3 \mathrm{~d}^{4} \mathrm{~F}_{J}^{\mathrm{o}}$ levels (with the exception of the $J=9 / 2$ level, the decay of which falls into a much longer-wavelength band) were observed in EUV spectra recorded on foil-excited ion beams of $\mathrm{Ti}, \mathrm{Fe}$, and $\mathrm{Ni}$ at Bochum [60]. (Having been involved in the latter experiment, I dare to report my relief that the two evaluations agreed on the positions of the $3 \mathrm{~s} 3 \mathrm{p} 3 \mathrm{~d}^{4} \mathrm{~F}_{J}^{\mathrm{o}}$ levels.) An important point about both experiments is the high density environment (solid-state density inside the foil of the fast-ion beam experiment, $n_{e} \approx 10^{24} \mathrm{~cm}^{-3}$, and not quite as high a density in the laser-produced plasma, maybe $n_{e} \approx 10^{20-22} \mathrm{~cm}^{-3}$ at the time) which - as stated above-facilitates the excitation of multiply excited levels. After the ion beam has left the exciter foil, the ambient vacuum typically is of $p \approx 10^{-6}$ mbar.

The elusive $J=9 / 2$ level decay has reappeared and demonstrated its role in a different context. Among the prominent emission lines of the solar corona is "the green iron line", the magnetic dipole $(M 1)$ transition $(\lambda \approx 530.3 \mathrm{~nm})$ in the FeXIV $3 \mathrm{~s}^{2} 3 \mathrm{p}{ }^{2} \mathrm{P}^{\mathrm{o}}$ ground term of the Al-like ion of iron. Three types of experiments have aimed at measuring the transition rate, and the results have been strikingly different, considering the accuracies claimed for such measurement techniques (for a detailed discussion and individual references, see Reference [61]). In short, two measurements at electron beam ion traps (EBIT) agreed best with what had been predicted from a combination of (rather straightforward) Racah algebra and the experimental transition energy (accurate wavelength measurements). Two measurements employing electrostatic (Kingdon) ion traps deviated some 2 to $5 \%$ from this (disregarding the measurement uncertainties here), and a measurement at the TSR heavy-ion storage ring differed by $8 \%$, all differences pointing to a lower transition rate (longer level lifetime). Thus, all of the measurements employed ion traps with excellent vacuum (very low density) but the trend of the deviations from the perceived-to-be-true atomic level lifetime value of about $16.7 \mathrm{~ms}$ was reminiscent of beam-foil spectroscopy, where the excitation takes place in a high-density environment before the observation occurs in a low-density environment. At high density, frequent collisions result in the excitation of many high-lying levels, the decay of which causes cascade repopulation of lower levels; this process can systematically distort the decay curves of the latter levels and usually results in apparent lifetimes that are longer than the true ones. Then, where is the origin of the suspected systematic error caused by a poorer vacuum?

In an EBIT, the excitation of the ions of interest takes place inside the actual ion trap at an excellent high vacuum, especially in a cryogenic EBIT cooled by liquid He (vacuum $p \approx 10^{-10}$ mbar or better). Here, the lifetime measurement result agreed with expectation and can, in fact, be used to test theory. The ions for the Kingdon trap experiment (operated maybe at $p \approx 10^{-8} \mathrm{mbar}$ ) were provided by an electron cyclotron resonance (ECR) ion source and then sent to the ion trap. In the ECR ion source, a plasma discharge is operated at not quite such a high vacuum (maybe $p \approx 10^{-6}$ mbar), and multiple excitations may be possible. The Heidelberg TSR heavy-ion storage ring ( $\left.p \approx 10^{-10} \mathrm{mbar}\right)$ draws ions from a regular accelerator built in the days when high vacuum meant $p \approx 10^{-6}$ mbar; moreover, the tandem accelerator at Heidelberg used a foil or gas stripper to produce highly charged ions, and thus, the production of highly excited ions is a given. However, the question is whether in Al-like ions there is a high-lying level of a lifetime long enough not only to survive the transfer to the storage ring $(\approx 10 \mu \mathrm{s})$ but also to affect the lifetime measurement of a level with a multi-millisecond lifetime, an effect not seen in many earlier measurements on other ion species. The answer is yes, there is: the $3 \mathrm{~s} 3 \mathrm{p} 3 \mathrm{~d}{ }^{4} \mathrm{~F}_{9 / 2}^{\mathrm{o}}$ level, with theoretical predictions very close to the lifetime of the $3 \mathrm{~s}^{2} 3 \mathrm{p}^{2} \mathrm{P}_{3 / 2}^{\mathrm{o}}$ level. Measurements on the Al-like ions of $\mathrm{Fe}, \mathrm{Co}$, and $\mathrm{Ni}(\mathrm{Z}=26-28)$ [61] corroborate the assumption that there is such a cascade contribution, but the associated signal is weak. The lifetime evaluation results therefore are too imprecise to yield a meaningful lifetime value of the "culprit" level. This small contribution, however, is sufficient to perturb the intended high-accuracy lifetime measurements 
on the $3 s^{2} 3 p^{2} \mathrm{P}_{3 / 2}^{\mathrm{o}}$ level of principal interest. An accurate lifetime measurement on that lower level is of particular interest because it might test a detail of atomic structure (the electron anomalous magnetic moment (EAMM) contribution to the $M 1$ line strength, an uncommonly large quantum electrodynamics (QED) effect at $0.45 \%$; see Reference [62]). It has been conjectured that a test of the EAMM might reveal the presence of "new physics beyond the Standard Model". As it happens, the scatter of the various predictions for the level lifetime mentioned above so far is larger than the small effect searched for and larger than the claimed experimental uncertainty reached so far. Atomic structure computations as well as experiment are being challenged to improve for a decisive step further in accuracy.

\subsection{Na-Like Ions: The $2 p^{5} 3 s 3 p^{4} D_{7 / 2}-2 p^{5} 3 s 3 d^{4} F_{9 / 2}^{o}$ Transition}

The $3 s-3 p$ and $3 p-3 d$ lines of singly excited Na-like ions stand out in many spectra and thus help the experimenter in the search for calibration lines and the subsequent establishment of a wavelength scale. This process is facilitated by the fact that, in the spectrum of ions with a single valence electron outside closed shells, there are just a few prominent lines. In contrast, most of the spectra of core-excited ions are calculated to be rich in lines; there are open shells with many coupling opportunities, and there are competing decay channels. Hence, predictions are less accurate and relative line intensities are generally lower and less easily predicted. There also is autoionization, which, for example, has been studied with the Na-like ion $\mathrm{Si}^{3+}$ [63]. However, I am putting emphasis on photon detection, which is more likely to succeed if autoionization is suppressed as is the case for high-spin and high- $J$ levels. These levels are much more limited in the number of their decay paths and, because of less level mixing, may be computed relatively accurately. For example, C. Jupén et al. [64] have identified the most prominent line of the multiplet, $2 \mathrm{p}^{5} 3 \mathrm{~s} 3 \mathrm{p}^{4} \mathrm{D}_{7 / 2}-2 \mathrm{p}^{5} 3 \mathrm{~s} 3 \mathrm{~d}^{4} \mathrm{~F}_{9 / 2}^{\mathrm{o}}$, in the spectra of a number of Na-like ions. As this means a single spectral line in a given element, any such classification might seem daring, but would be helped by similar observations of many elements in an isoelectronic sequence. In fact, several of the identifications proposed by Jupén et al. concerned lines that had been classified differently before, and only the combination of many measurements ascertained the interpretation and systematic consistency of the sample. In a second step, Jupén et al. [65] have analyzed the line pattern of the $2 p^{5} 3 s 3 p{ }^{4} \mathrm{D}-2 \mathrm{p}^{5} 3 \mathrm{p}^{2}{ }^{4} \mathrm{D}$ multiplet (and some others) in the Na-like spectra of $\mathrm{S}, \mathrm{Cl}$, and Ar. This analysis encompasses quite a number of spectral features in computation and measurement, corroborating the identification analogously to a multi-digit combination lock.

Jupén et al. used the Cowan code (see Reference [66,67]) for guidance, a nonrelativistic Hartree-Fock (HF) atomic structure code that permits the external scaling of the Slater parameters. While the code yields sometimes shockingly inaccurate transition wavelengths when used in the ab initio mode (wavelength uncertainties of $20 \%$ are common), the results are much closer to reality when the Slater parameters are subjected to "standard scaling" values. The results can be notably improved even further by a least-squares fit of some of the computed wavelengths to experimental wavelength data, with the adjustment being performed on the atomic parameters. A semi-empirically scaled result has a limited predictive power per se (which, in contrast, we would expect from a valid theory), but after such scaling of key atomic parameters, the relative properties in a computed spectrum still correspond to the underlying atomic structure theory. Thus, lines not included in the scaling process as well as isoelectronic trends can now be predicted reasonably well. In the work by Jupén et al. [64], the ab initio results are listed alongside the scaled ones. The former already represent a rather good approximation because the valence electrons are close to hydrogenic orbits without too much core polarization, while the scaled results match experiment very well indeed (Table 1). They also indicate with high reliability the transition wavelengths for the elements not covered at the time, which were about as many as had been measured.

While semi-empirically scaled calculations are very helpful, one wishes for ab initio computations of accuracy to prevent observer bias in the selection of the reference lines used in the least-squares fitting procedure and other human errors. Such a relativistic MCDF computation for this specific 
case has been performed by M.H. Chen soon after [68], covering 18 elements with $18 \leq Z \leq 92$, that is, for but a few of the elements of Table 1. In fact, explicit data are given for only three elements (Ar $Z=18$, Ti $Z=22$, and Fe $Z=26$ ) and only for the electron configuration of the lower level of the transition of present interest and, thus, not for the particular transition of present interest. Since then, M. J. Vilkas and Y. Ishikawa have applied their Multi-reference Møller-Plesset (MR-MP) approach [69-71] to all 14 elements with $17 \leq Z \leq 30$. Table 1 shows that, for the lower- $Z$ elements of this sequence, the deviation of the MR-MP results from the scaled HF results is only about a fourth of that of the unscaled HF results. At the high- $Z$ end of this range, the ab initio computation agrees closely with the results of the scaled HF calculation .

Table 1. Comparison of experimental $2 s^{2} 2 p^{5} 3 s 3 p{ }^{4} D_{7 / 2}-2 s 2 p^{5} 3 s 3 d{ }^{4} F_{9 / 2}^{o}$ transition wavelengths (in $\mathrm{nm}$ ) in ions of the $\mathrm{Na}$ I isoelectronic sequence with single-configuration Hartree-Fock (HF, Cowan code) calculations, semi-empirical adjustment of the same by fitting the calculation to the data, and ab initio Multi-reference Møller-Plesset (MR-MP) calculations.

\begin{tabular}{ccccc}
\hline $\mathbf{Z}$ & Experiment & HF $^{\mathbf{a}}$ & Fit $^{\mathbf{a}}$ & MR-MP $^{\mathbf{b}}$ \\
\hline 17 & $53.270 \pm 0.010^{\mathrm{a}}$ & 52.75 & 53.267 & 53.307 \\
18 & $47.134 \pm 0.005^{\mathrm{a}}$ & 46.71 & 47.122 & 47.213 \\
19 & $42.29 \pm 0.01^{\mathrm{c}}$ & 41.97 & 42.305 & 42.391 \\
20 & $38.420 \pm 0.005^{\mathrm{c}}$ & 38.13 & 38.415 & 38.473 \\
21 & $35.20 \pm 0.01^{\mathrm{c}}$ & 34.96 & 35.198 & 35.252 \\
22 & $32.487 \pm 0.002^{\mathrm{a}}$ & 32.28 & 32.489 & 32.488 \\
23 & $30.17 \pm 0.01^{\mathrm{c}}$ & 29.98 & 30.169 & 30.179 \\
24 & $28.167 \pm 0.005^{\mathrm{a}}$ & 27.99 & 28.160 & 28.170 \\
25 & $26.40 \pm 0.01^{\mathrm{c}}$ & 26.25 & 26.398 & 26.407 \\
26 & $24.836 \pm 0.005^{\mathrm{a}}$ & 24.71 & 24.839 & 24.848 \\
27 & $23.44 \pm 0.01^{\mathrm{c}}$ & 23.33 & 23.448 & 23.458 \\
28 & $22.200 \pm 0.010^{\mathrm{a}}$ & 22.09 & 22.198 & 22.209 \\
29 & $21.070 \pm 0.005^{\mathrm{a}}$ & 20.97 & 21.068 & 21.079 \\
30 & - & 19.95 & 20.039 & 20.051 \\
\hline
\end{tabular}

a Jupén et al. [64]; lines partly reassigned from earlier work; ${ }^{\mathrm{b}}$ Vilkas and Ishikawa [72]; ${ }^{\mathrm{c}}$ this work.

\section{Recent Work on the $2 p^{5} 3 s 3 p^{4} D_{7 / 2}-2 p^{5} 3 s 3 d{ }^{4} F_{9 / 2}^{o}$ Transition}

At the time of the experiment and data reanalysis described by Jupén et al. [64], there were no experimental data available for six of the elements in the range $17 \leq Z \leq 29$. Various beam-foil measurements at Bochum by now have covered the wavelength range in which the $2 p^{5} 3 s p^{4} D_{7 / 2}$ $-2 \mathrm{p}^{5} 3 \mathrm{~s} 3 \mathrm{~d}^{4} \mathrm{~F}_{9 / 2}^{\mathrm{o}}$ transition in Na-like ions is expected. Sample spectra are shown in Figures 1-8. The new experiments used the same equipment and procedures as described by Jupén et al. [64]. On the accelerator side, this was the 4 MV Dynamitron Tandem heavy-ion accelerator at the Bochum DTL laboratory, equipped with a Middleton-type sputter source that is capable of producing rather intense ion beams of most elements. The high voltage terminal construction and the tandem accelerator working principle on one side and the quest for Na-like ions (11 electrons) after ion-foil interaction on the other set has a practical upper limit of $Z \approx 30$. The ion beams of a given ion species and energy were guided to a vacuum chamber with a displaceable foil wheel and passed through a thin (typically $10 \mu \mathrm{g} / \mathrm{cm}^{2}$ ) carbon foil. Light from the foil-excited ion beam was dispersed by a grazing-incidence spectrometer (McPherson Model 247 scanning EUV monochromator, grating 600 $\mathrm{L} / \mathrm{mm}, \mathrm{R}=2.2 \mathrm{~m}$ ) and detected by a channeltron. The spectra were Doppler corrected for the known ion energy (in the few-MeV range for the lighter ions, up to $30 \mathrm{MeV}$ for the heavier ones) and were calibrated with known in-beam reference lines. The linearity of the experimental wavelength scale was improved by monitoring the spectrometer exit slit head displacement during spectral scans by a Moiré fringe length gauge. 
For a typical slit width of $50 \mu \mathrm{m}$, the line width produced by this EUV spectrometer was $0.035 \mathrm{~nm}$. While at wavelengths near $35 \mathrm{~nm}$ this corresponds to a resolving power of $\lambda / \Delta \lambda \approx 1000$, in the same experiment at a wavelength near $\lambda=17 \mathrm{~nm}$, the resolving power is only 500 . The typical step motor increment was chosen to yield 3 to 4 channels per line width. With narrower slits, the resolving power increases but the detection solid angle and thus the signal rate decreases. Moreover, the wavelength increments have to be smaller in order to maintain a sensible coverage of each line profile. The measurement is further affected by the finite time the exciter foil lasts under ion beam irradiation. A higher ion beam current is beneficial for the data rate, but it also increases the need for foil replacement and the risk of introducing artefacts to the spectra at the time of the beginning of foil breakage (which is not necessarily noted because the data recording time interval is normalized to the integrated ion beam current behind the foil). Replacement foils, even of the same production batch, do not all work out similarly in terms of light yield. Last, but not least, accelerator run time is scarce, especially at a multi-user facility. Covering a wide spectrum in detail and with high statistical reliability often is prohibitively costly in terms of beam time. It might have many advantages to have dedicated accelerator runs for one element after the other in order to cover all elements of present interest in sequence and sufficient detail as well as a capture of the spectral vicinity of a feature of interest. However, the present data have been culled from different measurements, executed over the time of several years. Consequently, the ion beam energy was not always at the optimum indicated by Delaunay [73] or Shima et al. [74], the spectral coverage was not necessarily tailored for the optimum coverage of the $2 p^{5} 3 s 3 p{ }^{4} D_{7 / 2}-2 p^{5} 3 s 3 d{ }^{4} F_{9 / 2}^{o}$ and all related lines, and the proper bracketing of the line of present principal interest by calibration lines was not considered. This becomes apparent in the sample spectra shown and discussed below, and it limits the accuracy of the measurements, which are included in Table 1. As it happens, none of the new measurements reaches an accuracy quite as high as the older ones, although they fully corroborate the earlier analysis on the totally different set of elements. Nevertheless, such data recorded "in passing" evidently have their value, even as sometimes only hindsight reveals the treasures.

\section{Available Data}

Spectroscopic data have been published in many journals or institutional reports. It is very helpful that compilations exist and that some of them have involved a critical evaluation of the data. However, it is a daunting task to strive for completeness and to keep up with corrections and updates. For example, while writing this manuscript, the numbers of lines of a specific sample listed in the NIST ASD online database [75] increased by some $10 \%$ for some elements. One set of samples comprised Ne- to P-like spectra data holdings in the wavelength interval $10-90 \mathrm{~nm}$. The typical number of entries for each element was in the range 300 to 550 lines, with Ti VIII-XIII being the top ranking one with 743 entries, Ca VI-XI having only 58 entries, $\mathrm{Cu}$ XV-XX having 148 lines, and Zn XVI-XXI having none. The Kelly tables [76] — which have not been updated in several decades—list only a few (but several) $\mathrm{Zn}$ lines in the sample range. Clearly, this difference in coverage is a result of the earlier (1970s) interest in controlled fusion device research which asked for data on elements up to (but not heavier than) $\mathrm{Ni}$ $(Z=28)$. At the time, heavy elements were seen as a detrimental contamination of any fusion plasma. $\mathrm{Cu}$ evidently has found some interest (partly because $\mathrm{Cu}$ contamination from antennas and electrical conductors inside plasma vessels had to be expected), and $\mathrm{Zn}$ has found very little. The CHIANTI database (see Reference [77] for their version 8) is oriented towards solar observations, and therefore, the interest is on elements that are most abundant in the solar corona; $\mathrm{Cu}$ and $\mathrm{Zn}$ are but rather minor contributors to solar spectra. The poor representation of Ca data in the NIST ASD database reflects the fact that $\mathrm{Ca}$ is difficult to exploit as a light source. Recent work at a tokamak plasma has indicated possible inconsistencies in the term analysis of highly charged Ca ions [78]. Of course, the above sample does not cover all charge states that might be present in the data.

The study by Jupén et al. [64] included beam-foil spectroscopic data recorded at the Bochum tandem accelerator. Since then, further measurements have addressed the EUV spectra of all elements 
from $\mathrm{K}$ to $\mathrm{Zn}$. Local development work on the commercial sputter ion source of the accelerator has been essential in producing high output currents of various elements that used to be claimed "difficult". Some of these currents (for $\mathrm{K}, \mathrm{Ca}$, and $\mathrm{Zn}$ ) nevertheless remained lower (by an order of magnitude) than the ion currents achieved for others $(\mathrm{Ti}, \mathrm{Ni}$, and $\mathrm{Cu}$ ). Moreover, the accelerator terminal voltage limits the ion beam energy that can be provided. Hence, there is a technical limit to the range of elements along an isoelectronic sequence that can be produced in the desired Na-like ion charge state. Consequently, our sample spectra reach only up to Co $(Z=27)$. Of the iron group elements, Ti $(Z=22), \mathrm{Fe}(Z=26), \mathrm{Ni}(Z=28)$, and $\mathrm{Cu}(Z=29)$, some of them observed in experiments elsewhere, have already been discussed by Jupén et al. [64]. Sample spectra of the vicinity of the $2 p^{5} 3 s 3 p^{4} D_{7 / 2}-$ $2 \mathrm{p}^{5} 3 \mathrm{~s} 3 \mathrm{~d}{ }^{4} \mathrm{~F}_{9 / 2}^{\mathrm{o}}$ transition are shown in Figure 1 on K, Figure 2 on Ca, Figure 3 on Sc, Figure 4 on V, Figure 5 on Cr, Figure 6 on Mn, Figure 7 on Co, and Figure 8 on Zn. In most of the spectra, all the prominent lines are known, except for the spectrum of $\mathrm{Ca}$, whereas in the spectrum of $\mathrm{Zn}$, practically all lines remain to be classified. The information associated with the individual spectra is given in the captions.

Prominent in most of the spectra shown are the $3 p-3 d$ transitions in singly excited Na-like ions. These are, of course, closely related to the $2 p^{5} 3 s 3 p^{4} D_{7 / 2}-2 p^{5} 3 s 3 d{ }^{4} F_{9 / 2}^{o}$ in the multiply excited $\mathrm{Na}^{*}$-like ions. Both are $3 \mathrm{p}-3 \mathrm{~d}$ transitions, but the active electron experiences a different electron core. Consequently, the transition energies scale differently with $Z$, as becomes obvious by the migration of the $3 p-3 d$ lines along the isoelectronic sequence from the long-wavelength edge of the spectrum shown for $\mathrm{K}$ (Figure 1, with the $\mathrm{Na}^{*}$-like line in the center) to an actual blend with the line of principal interest in $\mathrm{Co}$ (Figure 7). A spectrum of $\mathrm{Zn}$ has been included in our plot presentation for the purpose of demonstrating visually that the proper charge state of interest in this element was beyond reach. The evidence for this lies in the fact that the usually strong $\mathrm{ZnXX}$ lines, that is the same spectrum as the hoped-for weak line of $Z n X X^{*}$, were not seen. Our spectrum demonstrates at the same time how poor the literature coverage of the $\mathrm{Zn}$ spectrum is.

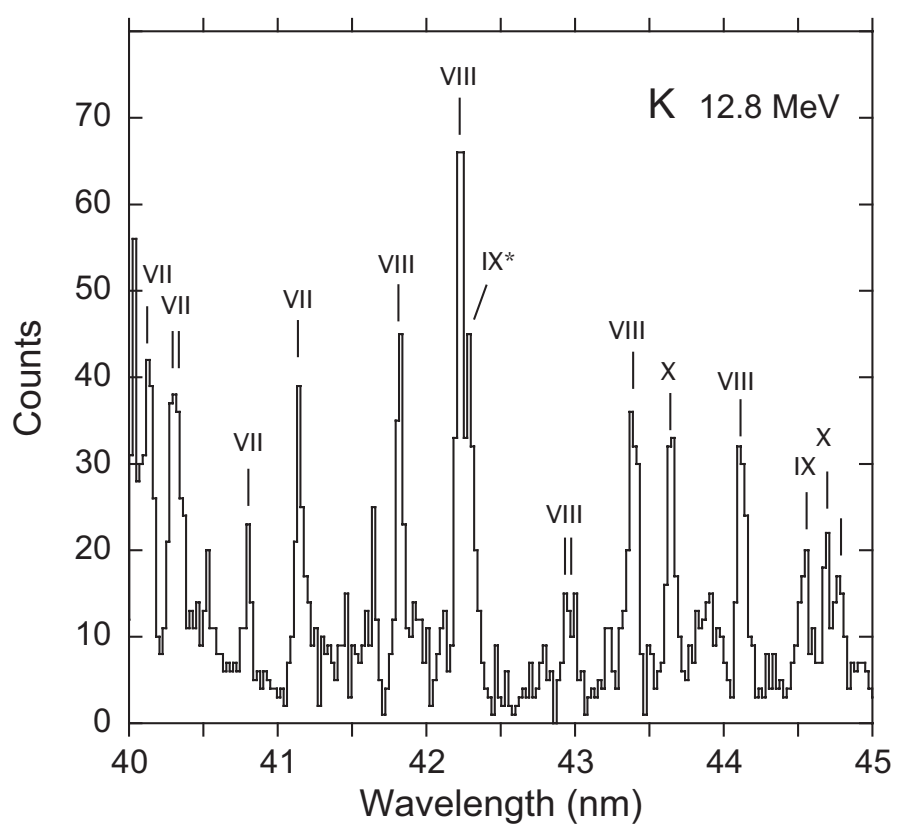

Figure 1. Beam-foil spectrum of ${ }^{39} \mathrm{~K}$ recorded at an ion beam energy of $12.8 \mathrm{MeV}$, close to the optimum ion beam energy for the production of the KIX spectrum [74]: Line width (full width at half maximum, FWHM) is $0.06 \mathrm{~nm}$. The more prominent lines are labeled by the spectrum number [75]. The KIX* line of interest is partly blended with a stronger line of K VIII. 


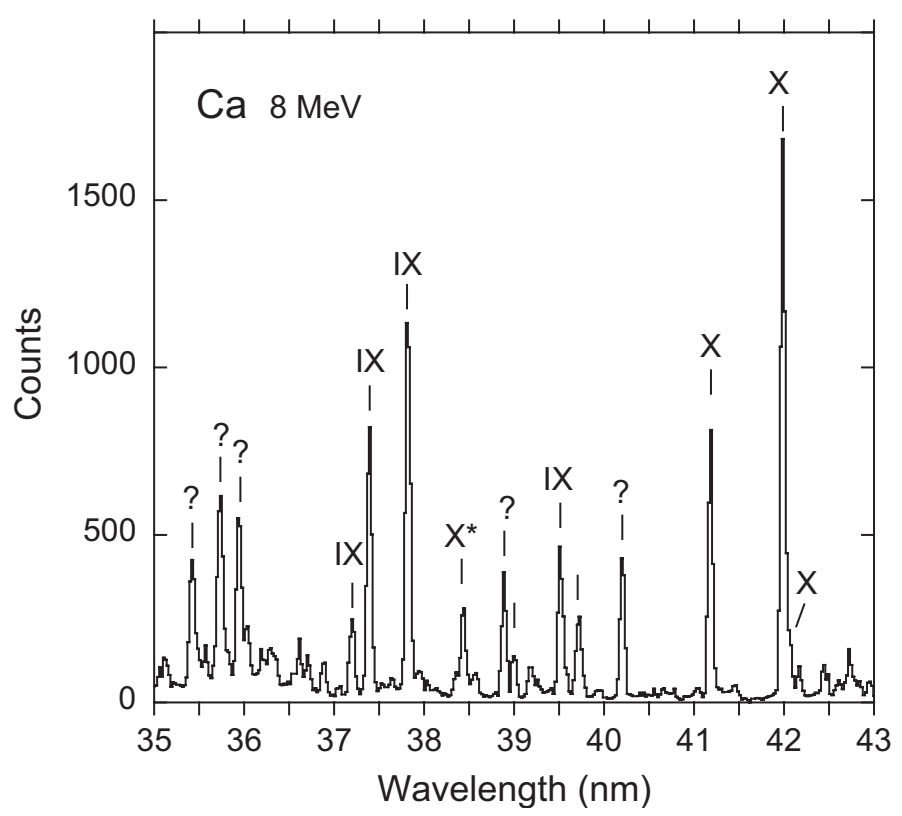

Figure 2. Beam-foil spectrum of ${ }^{40} \mathrm{Ca}$ recorded at an ion beam energy of $8 \mathrm{MeV}$, slightly lower than the optimum ion beam energy for the production of the Ca X spectrum [74]: Spectra taken at $11 \mathrm{MeV}$ are very close to this one in appearance. Line width (FWHM) is $0.06 \mathrm{~nm}$. The more prominent ones among the lines are labeled by the spectrum number [75]. A number of lines remains unidentified, owing to the spectrum analysis that for $\mathrm{Ca}$ is much less complete than for other elements. The Ca $\mathrm{X}^{*}$ line of interest (near $\lambda=38.5 \mathrm{~nm}$ ) is accompanied by unidentified other lines, but the wavelength determination is hardly affected.

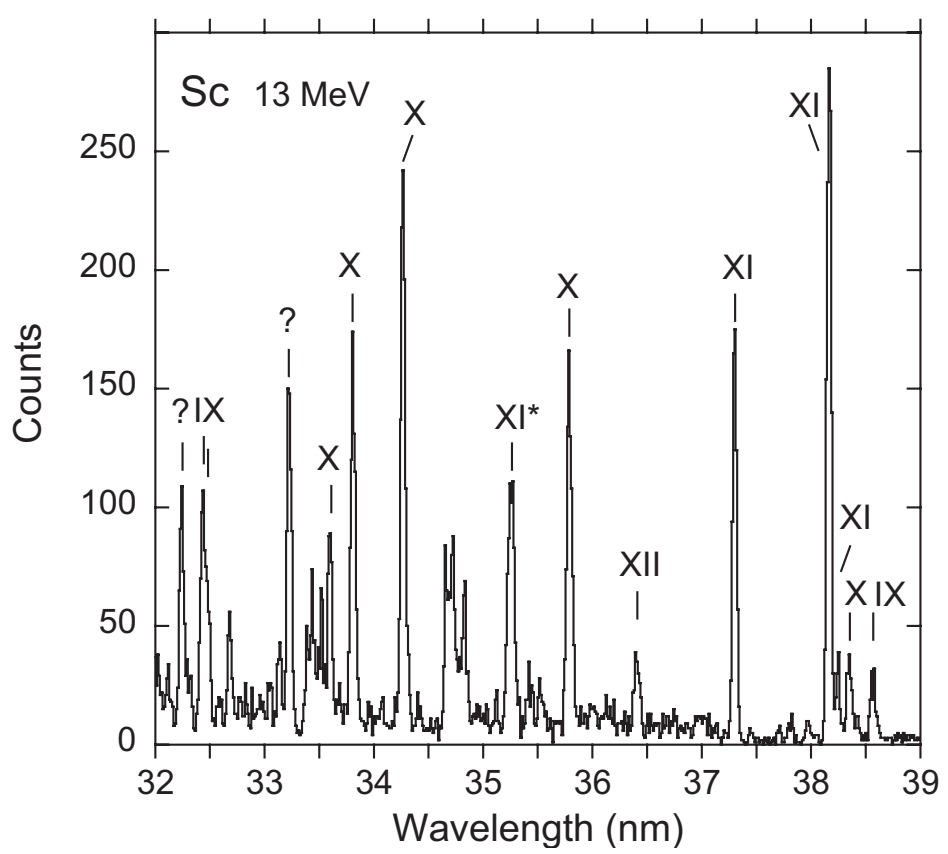

Figure 3. Beam-foil spectrum of ${ }^{45} \mathrm{Sc}$ recorded at an ion beam energy of $13 \mathrm{MeV}$, near the optimum ion beam energy for the production of the Sc XI spectrum [74]: Line width (FWHM) is $0.045 \mathrm{~nm}$. The more prominent ones among the lines are labeled by the spectrum number [75]. Near $37.3 \mathrm{~nm}$ and $38.15 \mathrm{~nm}$ lie the prominent and well-known 3p-3d transitions of singly excited Sc XI. The Sc XI* line of present interest at $\lambda \approx 35.2 \mathrm{~nm}$ appears slightly broader than the other lines, so that a line blend has to be suspected, which enlarges the uncertainty of the wavelength determination. 


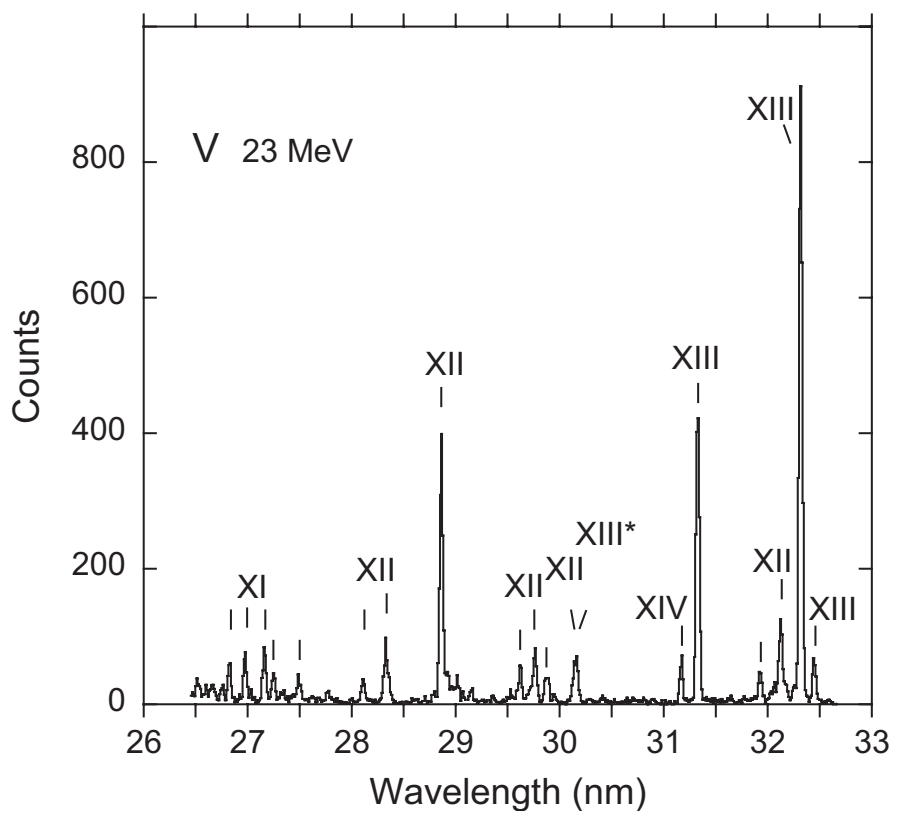

Figure 4. Beam-foil spectrum of ${ }^{51} \mathrm{~V}$ recorded at an ion beam energy of $20 \mathrm{MeV}$, near the optimum ion beam energy for the production of the V XIII spectrum [74]: Line width (FWHM) is $0.035 \mathrm{~nm}$. The more prominent ones among the lines are labeled by the spectrum number [75]. Near $31.3 \mathrm{~nm}$ and $32.3 \mathrm{~nm}$ lie the prominent and well-known 3p-3d transitions of singly excited V XIII. The V XIII* line of present interest at $\lambda \approx 30.2 \mathrm{~nm}$ appears slightly broader than the other lines. The blend with a V XII line enlarges the uncertainty of the wavelength determination.

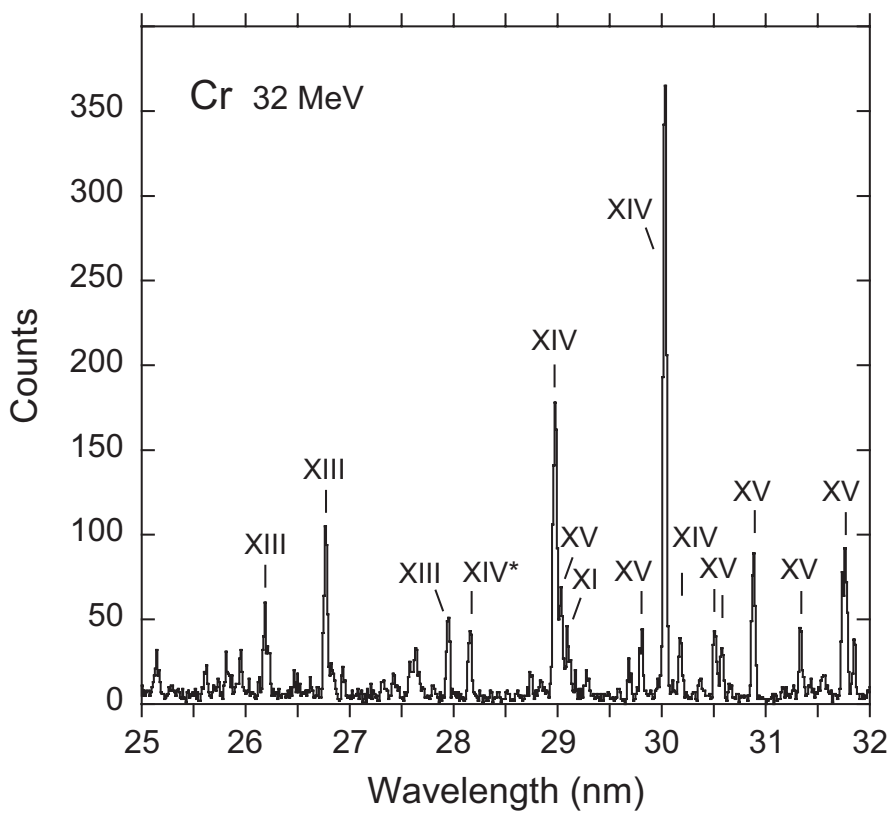

Figure 5. Beam-foil spectrum of ${ }^{52} \mathrm{Cr}$ recorded at an ion beam energy of $32 \mathrm{MeV}$, near the optimum ion beam energy for the production of the Cr XIV spectrum [74]: Line width (FWHM) is $0.035 \mathrm{~nm}$. The more prominent ones among the lines are labeled by the spectrum number [75]. Near $29 \mathrm{~nm}$ and $30 \mathrm{~nm}$ lie the prominent and well-known 3p-3d transitions of singly excited Cr XIV. The shortest-wavelength line of this multiplet suffers from a blend with $\mathrm{Cr} X \mathrm{I}$ and possibly other lines, which affects the reliability of the wavelength determination of this calibration line. The $\mathrm{Cr} \mathrm{XIV}^{*}$ line of present interest lies at $\lambda \approx 28.2 \mathrm{~nm}$. 


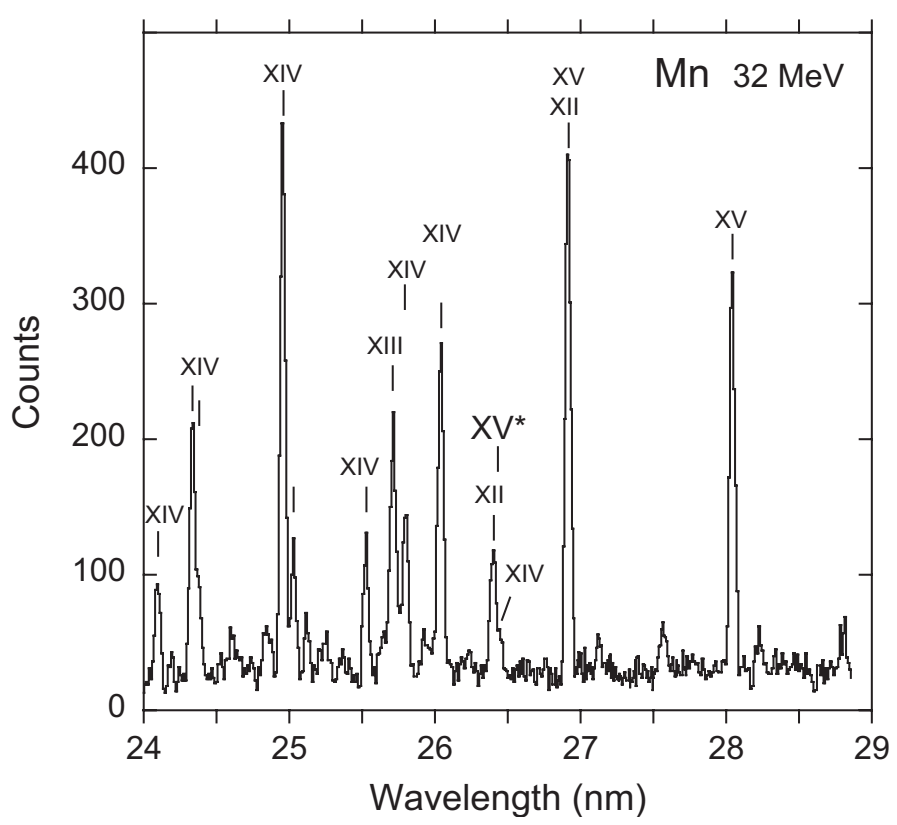

Figure 6. Beam-foil spectrum of ${ }^{55} \mathrm{Mn}$ recorded at an ion beam energy of $32 \mathrm{MeV}$, near the optimum ion beam energy for the production of the MnXV spectrum [74]: Line width (FWHM) is $0.045 \mathrm{~nm}$. The more prominent ones among the lines are labeled by the spectrum number [75]. Near $26.99 \mathrm{~nm}$ and $28 \mathrm{~nm}$ lie the prominent and well-known 3p-3d transitions of singly excited Mn XV. The shorter-wavelength line of the multiplet suffers from a blend with Mn XI, which affects the reliability of the wavelength determination of this calibration line. The $\mathrm{MnXV}^{*}$ line of present interest lies at $\lambda \approx 26.4 \mathrm{~nm}$ and is part of a blend with lines of Mn XII and Mn XIV. 


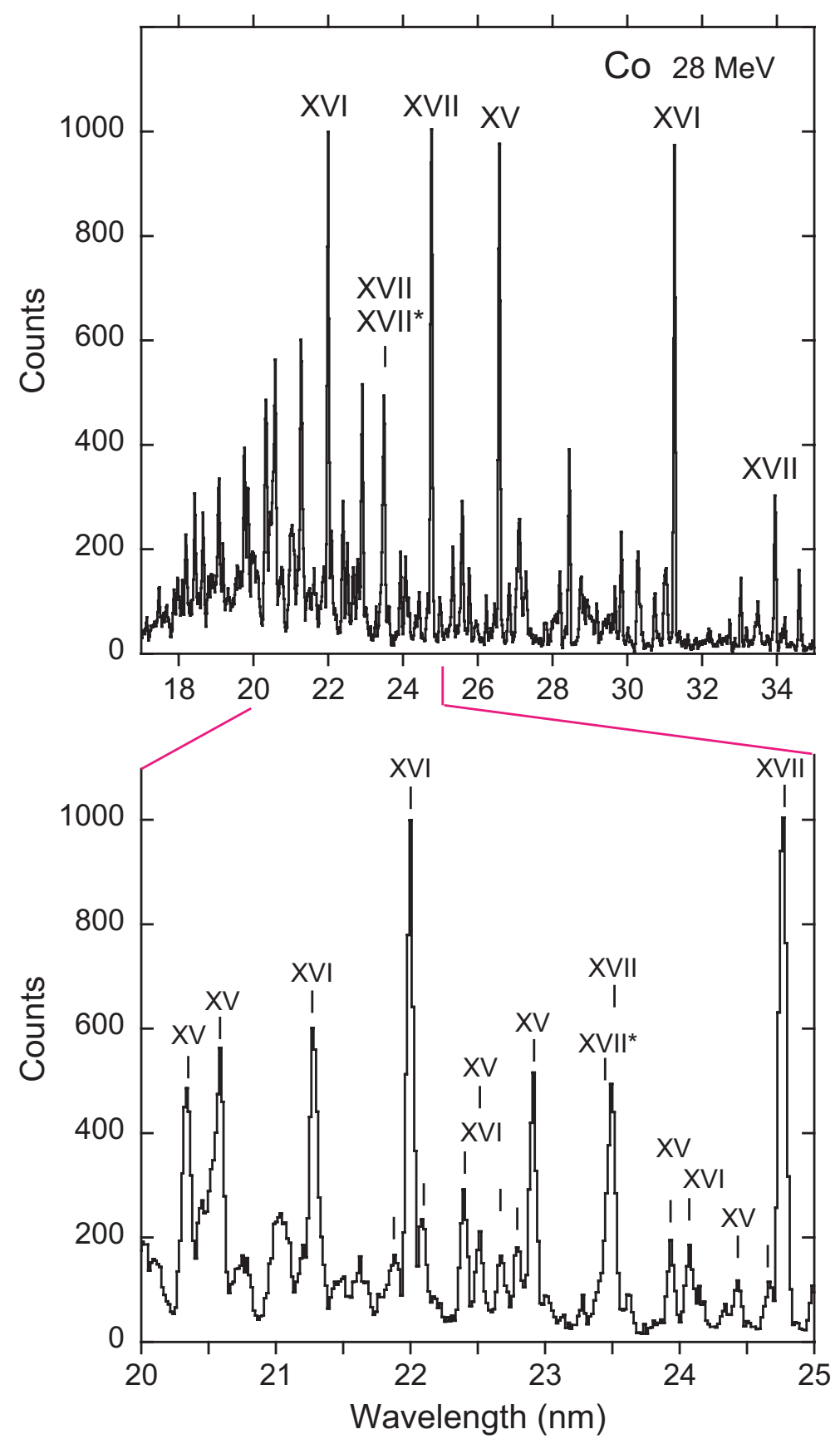

Figure 7. Beam-foil spectrum of ${ }^{59} \mathrm{Co}$ recorded at an ion beam energy of $28 \mathrm{MeV}$, somewhat below the optimum ion beam energy of about $40 \mathrm{MeV}$ for the production of the CoXVII spectrum [74]: Line width (FWHM) is $0.06 \mathrm{~nm}$. The more prominent ones among the lines are labeled by the spectrum number [75]. In the upper spectrum, the prominent lines yield a reliable wide-range wavelength calibration. However, the CoXVII* line of present interest lies at $\lambda \approx 23.4 \mathrm{~nm}$ and is part of a blend with a prominent $3 \mathrm{p}-3 \mathrm{~d}$ line. The lower part of the figure expands the display of the vicinity of the CoXVII* line and reveals that the line of interest is a minor part of that line blend. 


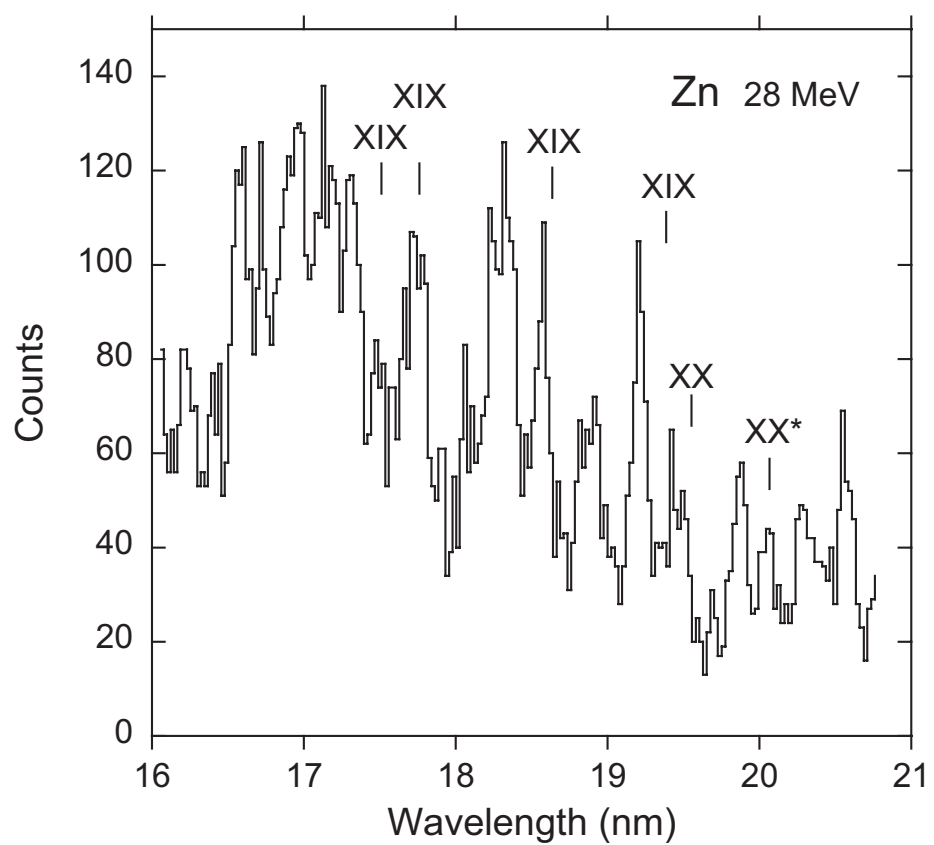

Figure 8. Beam-foil data obtained at an ion beam energy of $28 \mathrm{MeV}$, with an observation $2 \mathrm{~mm}$ downstream (roughly $0.2 \mathrm{~ns}$ after excitation), slits of $0.12 \mathrm{~mm}$, and line width of $0.09 \mathrm{~nm}$ : This ion beam energy is much lower than the production optimum near $65 \mathrm{MeV}$ [74], which is beyond reach of the Bochum ion accelerator. Moreover, the ion source yields $\mathrm{Zn}$ ions at a significantly lower current than has been achieved with some other elements. The most abundant spectrum expected is Zn XVI, while the charge state fraction of interest, $\mathrm{Zn}^{19+}$ (spectrum $\mathrm{ZnXX}$ ), is predicted to amount to a few percent at best [74]. The positions of all $\mathrm{Zn}$ lines listed by Kelly [76] in the wavelength range depicted are marked, but there are no consistent matches. A suitable indicator whether the proper charge state has been produced is the appearance of prominent lines of singly excited $\mathrm{Zn} X X$, for example, the 3p-3d line at $19.538 \mathrm{~nm}$ [76], but that transition shows as a weak and blended line at best. Consequently, the line of interest in $\mathrm{ZnXX}$ must be too weak to observe in this spectrum. There actually is a line at $20.05 \pm 0.02 \mathrm{~nm}$ that is compatible with the predicted position of $20.039 \mathrm{~nm}$ [64], but the line seen is much stronger than the line of interest in $\mathrm{ZnXX}$ could be under the circumstances, suggesting a blend with some stronger, unidentified line. CHIANTI [77] lists very few Zn lines in this wavelength range of 16-20.7 nm (the NIST ASD database [75] lists none), and none of these is seen here. The vast majority of the spectral structures in this $\mathrm{Zn}$ spectrum remains unidentified for now.

\section{Discussion and Outlook}

Few-electron multiply excited ions are helpful tools in plasma diagnostics. The high total angular momentum $(J)$ levels of such ions usually live much longer than their nearby relatives, and thus, they offer a different access to the measurement of atomic properties. A reliable knowledge of these properties is essential for the comprehensive modeling of simulated spectra and the interpretation of measured spectra. Early on, the satellite spectra of core-excited three-electron ions seemed to be all that could be expected to be useful for plasma diagnostics, but instruments of higher resolving power, the recognition of inner-shell photoionization in astrophysical sources, as well as experiments with $X$-ray lasers have extended the view to core-excited atomic systems with more than three electrons. In any case, levels with a high $J$ stand out and extend the diagnostic toolbox.

The analysis of the $2 p^{5} 3 s 3 p{ }^{4} D_{7 / 2}-2 p^{5} 3 p^{2}{ }^{4} D_{7 / 2}$ multiplet in the Na-like spectra of $S, C l$, and $\operatorname{Ar}[65]$ has been a door opener on atomic systems with a regularly filled electron core but multiple excitation in the outer shells. This largely nonrelativistic analysis has been followed up by, for example, a relativistic computation of the Fe $\mathrm{XVI}^{*} 2 \mathrm{p}^{5} 3 \ell 3 \ell^{\prime}$ levels [72]. At the time of the earlier study by Jupén et al. [64], the NIST ASD database had few such transitions in their holdings, but now, there are 
many line entries for ions of iron-group elements. In fact, many of these lines can now be identified straightaway in beam-foil spectra which are particularly productive in terms of multiple excitation.

The appearance of levels of high- $J$ relates to the excitation process because these levels cannot be excited in a single step ( $E 1$ transition) from the ground state but regularly require an intermediate high-lying level or a collision with other atomic systems. This poses an interesting challenge, which is reminiscent of the situation in beam-foil spectroscopy where excitation occurs in a high-electron density environment while the detection profits from the low-density environment experienced by the ion after leaving the exciter foil. When X-rays were detected from comets, their soft-X-ray spectra showed uncommon spectral characteristics. Charge-exchange (CX) processes have been invoked to explain the peculiarities in the interaction of comets with the solar wind [79]. However, outer space is largely a very-low density environment, and it soon became obvious that CX processes in this context ought to be studied in electron beam ion traps (EBIT) [80-83]. An electron beam ion trap continually provides the low-density environment, and thus, the level populations of the two light sources, beam-foil, and EBIT differ significantly [84,85]. However, in an EBIT, one can modulate the electron density as well, although the "high" electron density is some 13 orders of magnitude lower than that encountered in a solid. The high electron density (on the order of $n_{e} \approx 10^{11} \mathrm{~cm}^{-3}$ ) relates to the electron beam being switched on, as is necessary for ionization (producing highly charge ions) and excitation (most of the trapped ions are in their electronic ground state). When the electron beam is switched off, the strong magnetic field and the electrically charged drift tubes continue to act as a Penning ion trap [86]. Excited ions decay radiatively and mostly on a short timescale (usually within fs to ms). However, photons are still detected seconds later and even many seconds later if the vacuum is excellent. These photons originate from collisions among the stored ions and of ions with atoms or molecules of the residual gas. The more highly charged collision partner may capture an electron (or more) from the collision partner. This charge exchange (CX) often ends in an excited state, notably a high-angular momentum state, in particular, at very low $(\mathrm{eV})$ collision energies. Whereas most sources of highly charged ions provide ions at the $\mathrm{keV}$ to $\mathrm{MeV}$ energy scale, the ions produced and trapped in an EBIT can be manipulated so that the representative kinetic energies amount to no more than a few $\mathrm{eV}$. It is interesting to see in experiments how clearly the spectra change under such conditions, underlining the differences in the excitation process. Levels of maximum total angular momentum surely are of particular interest.

Acknowledgments: Y. Ishikawa and M.J. Vilkas (both then at the University of Puerto Rico, San Juan) have kindly provided unpublished results of their MR-MP computations.

Conflicts of Interest: The author declares no conflicts of interest.

\section{References}

1. Edlén, B. Atomic Spectra. In Encyclopedia of Physics; Flügge, S., Ed.; Springer: Berlin, Germany, 1964; Volume 27.

2. Wu, T.-Y. Auto-ionization in doubly excited helium and the $\lambda 320.4$ and $\lambda$ 357.5 lines. Phys. Rev. 1944, 66, 291. [CrossRef]

3. Pietenpol, J.R. Auto-ionization of the (1s2s2p) ${ }^{4} \mathrm{P}_{5 / 2}$ level in Li and $\mathrm{He}^{-}$. Phys. Rev. Lett. 1961, 7, 64. [CrossRef]

4. Gabriel, A.H. Dielectronic satellite spectra for highly-charged helium-like ion lines. Mon. Not. R. Astron. Soc. 1972, 160, 99-119. [CrossRef]

5. Kay, L. A van de Graaff beam as a source of atomic emission spectra. Phys. Lett. 1963, 5, 36-37. [CrossRef]

6. Bashkin, S.; Meinel, A.B. Laboratory excitation of the emission spectrum of a nova. Astrophys. J. 1964, 139, 413-415. [CrossRef]

7. Bashkin, S. Optical spectroscopy with Van De Graaff accelerators. Nucl. Instrum. Meth. 1964, 28, 88-96. [CrossRef]

8. Bashkin, S. A new method for studying the atom. Science 1965, 148, 1047-1053. [CrossRef] 
9. Kay, L. On the origins of beam-foil spectroscopy-I. Nucl. Instrum. Methods Phys. Res. Sect. B 1985, 9, 544-545. [CrossRef]

10. Bashkin, S. On the origins of beam-foil spectroscopy-II. Nucl. Instrum. Methods Phys. Res. Sect. B 1985, 9, 546-548. [CrossRef]

11. Berry, H.G. Multiply-excited states in beam-foil spectroscopy. Phys. Scr. 1975, 12, 5-20. [CrossRef]

12. Berry, H.G. Beam-foil spectroscopy. Rep. Prog. Phys. 1977, 40, 155-217. [CrossRef]

13. Mannervik, S. Optical studies of multiply excited states. Phys. Scr. 1989, 40, 28-52. [CrossRef]

14. Träbert, E. Radiative-Lifetime Measurements on Highly-Charged Ions. In Accelerator-Based Atomic Physics Techniques and Applications; Shafroth, S.M., Austin, J.C., Eds.; American Institute of Physics: Washington, DC, USA, 1997; pp. 567-607.

15. Bruch, R.; Paul, G.; Andrä, J.; Fricke, B. Auger transitions in Li-like and Be-like ions. Phys. Lett. A 1975, 53, 293-294. [CrossRef]

16. Schneider, D.; Bruch, R.; Schwarz, W.H.E.; Chang, T.C.; Moore, C.F. Identifications of Auger spectra from 2-MeV foil-excited carbon ions. Phys. Rev. A 1977, 15, 926-934. [CrossRef]

17. Bruch, R.; Rødbro, M.; Bisgaard, P.; Dahl, P. Time-delayed Li, Be and B autoionization spectra excited in low-energy (200 keV) single gas collisions. Phys. Rev. Lett. 1977, 39, 801-803. [CrossRef]

18. Dohmann, H.-D.; Liesen, D.; Pfeng, H. High resolution spectroscopy of prompt and metastable decaying levels in highly ionized argon, especially of the metastable ${ }^{3} \mathrm{P}_{2}$-state of $\mathrm{Ar}^{16+}$ and the ${ }^{4} \mathrm{P}_{5 / 2}$-state of $\mathrm{Ar}^{15+}$. Z. Phys. A 1978, 285, 171-176. [CrossRef]

19. Beiersdorfer, P.; Bitter, M.; Hey, D.; Reed, K.J. Identification of the $1 \mathrm{~s} 2 \mathrm{~s} 2 \mathrm{p}{ }^{4} \mathrm{P}_{5 / 2} \rightarrow 1 \mathrm{~s}^{2} 2 \mathrm{~s}^{2} \mathrm{~S}_{1 / 2}$ magnetic quadrupole inner-shell satellite line in the $\mathrm{Ar}^{16+} \mathrm{K}$-shell X-ray spectrum. Phys. Rev. A 2002, 66, 032504. [CrossRef]

20. Träbert, E. Lifetimes of lowest even-parity quartet levels of three-electron ions. Z. Phys. A 1985, 321, 51-55. [CrossRef]

21. Träbert, E. The lifetime of the $1 \mathrm{~s} 2 \mathrm{p}^{2}{ }^{4} \mathrm{P}$ state, $\mathrm{Li}^{0}-\mathrm{Si}^{11+}$; a comment on available data and suggestions for a recommended set of data. Nucl. Instrum. Methods Phys. Res. Sect. B 1987, 23, 287-290. [CrossRef]

22. Träbert, E.; Curtis, L.J. Comment on finestructure data of three-electron quartet states. Phys. Scr. 1985, 32, 599-601. [CrossRef]

23. Hellmann, H.; Träbert, E. Beam-foil spectroscopical study of the 1s2s2p and 1s2 $\mathrm{p}^{2}$ quartet levels of $\mathrm{Mg}^{9+}$ and $\mathrm{Al}^{10+}$. Nucl. Instrum. Methods Phys. Res. Sect. B 1985, 9, 611-613. [CrossRef]

24. Engström, L.; Hutton, R.; Reistad, N.; Martinson, I.; Huldt, S.; Mannervik, S.; Träbert, E. A new measurement of the $1 \mathrm{~s} 2 \mathrm{~s} 2 \mathrm{p}{ }^{4} \mathrm{P}^{\mathrm{o}}-1 \mathrm{~s} 2 \mathrm{p}^{2}{ }^{4} \mathrm{P}$ transitions in C IV: Wavelengths, fine structure intervals and lifetimes. Phys. Scr. 1987, 36, 250-254. [CrossRef]

25. Buchet, J.P.; Buchet-Poulizac, M.C.; Denis, A.; Désesquelles, J.; Druetta, M.; Martin, S.; Ouerdane, Y. Fine structure of the $1 \mathrm{~s} 2 \mathrm{~s} 2 \mathrm{p}{ }^{4} \mathrm{P}^{\mathrm{o}}$ and $1 \mathrm{~s} 2 \mathrm{p}^{2}{ }^{4} \mathrm{P}$ doubly excited states of lithiumlike Si XII. J. Phys. (Paris) Coll. Suppl. Au 1988, 49, 111-114.

26. Mannervik, S.; Short, R.T.; Sonnek, D.; Träbert, E.; Möller, G.; Lodwig,V.; Heckmann, P.H.; Blanke, J.H.; Brand, K. Bound triply excited states in neutral lithium. Phys. Rev. A 1989, 39, 3964-3968. [CrossRef]

27. Träbert, E.; Heckmann, P.H.; Doerfert, J.; Granzow, J. Search for the spectrally narrow radiative decay of $2 \mathrm{p}^{3}$ ${ }^{4} S_{3 / 2}^{o}$. J. Phys. B At. Mol. Opt. Phys. 1992, 25, L353-L358. [CrossRef]

28. Knystautas, E.J. Observation of a triply excited state in $\mathrm{He}^{-}$. Phys. Rev. Lett. 1992, 69, 2635-2637. [CrossRef]

29. Winter, H.; Aumayr, F. Hollow atoms. J. Phys. B At. Mol. Opt. Phys. 1999, 32, R39. [CrossRef]

30. Rosmej, F.B.; Dachicourt, R.; Deschaud, B.; Khaghani, D.; Dozières, M.; Šmìd, M.; Renner, O. Exotic X-ray emission from dense plasmas. J. Phys. B: At. Mol. Opt. Phys. 2015, 48, 224005. [CrossRef]

31. Träbert, E.; Armour, I.A.; Bashkin, S.; Jelley, N.A.; O’Brien, R.; Silver, J.D. The X-ray spectra of H-like, He-like and Li-like silicon ions after foil excitation. J. Phys. B At. Mol. Phys. 1979, 12, 1665-1676. [CrossRef]

32. Träbert, E.; Fawcett, B.C. Identification of satellite lines in the X-ray spectrum of foil-excited silicon. J. Phys. B At. Mol. Phys. 1979, 12, L441-L447. [CrossRef]

33. Armour, I.A.; Fawcett, B.C.; Silver, J.D.; Träbert, E. X-ray spectra and satellite classification of foil-excited Mg and Al. J. Phys. B At. Mol. Phys. 1980, 13, 2701-2709. [CrossRef]

34. Träbert, E.; Fawcett, B.C.; Silver, J.D. One- and two-electron one-photon satellite transitions in the X-ray spectrum of foil-excited F and Si. J. Phys. B At. Mol. Phys. 1982, 15, 3587-3597. [CrossRef] 
35. Bunge, C.F. Identification of bound states of core-excited negative lithium atoms in beam-foil experiments. Phys. Rev. Lett. 1980, 44, 1450-1452. [CrossRef]

36. Mannervik, S.; Astner, G.; Kisielinski, M. An optical transition in the negative lithium ion. J. Phys. B At. Mol. Phys. 1980, 13, L441-L444. [CrossRef]

37. Lodwig, V.; von Buttlar, H. Lifetime of the $1 \mathrm{~s} 2 \mathrm{p}^{3}{ }^{5} \mathrm{~S}^{\circ}$ level in the negative lithium ion. Phys. Scr. 1989, 39, 586-591. [CrossRef]

38. Hardis, J.E.; Berry, H.G.; Curtis, L.J.; Livingston, A.E. The $1 \mathrm{~s} 2 \mathrm{~s} 2 \mathrm{p}^{2}{ }^{5} \mathrm{P}_{1,2,3}-1 \mathrm{~s} 2 \mathrm{p}^{3}{ }^{5} \mathrm{~S}_{2}^{\mathrm{o}}$ transition in Ne VII. Phys. Scr. 1984, 30, 189-193. [CrossRef]

39. Träbert, E.; Blanke, J.H.; Heckmann, P.H.; Hellmann, H.M.; Möller, G. Ruhr-Universität Bochum, Dynamitron Tandem Laboratory. Unpublished work, 1986.

40. Brage, T.; Froese Fischer, C. The $1 \mathrm{~s} 2 \mathrm{~s} 2 \mathrm{p}^{2}{ }^{5} \mathrm{P}-1 \mathrm{~s} 2 \mathrm{p}^{3}{ }^{5} \mathrm{~S}$ transition in Be I-like ions. J. Phys. B At. Mol. Opt. Phys. 1988, 21, 2563-2569. [CrossRef]

41. Kwong, T.; Chung, K.T. $1 \mathrm{~s} 2 \mathrm{~s} 2 \mathrm{p}^{2}{ }^{5} \mathrm{P}-1 \mathrm{~s} 2 \mathrm{p}^{3}{ }^{5} \mathrm{~S}^{\mathrm{o}}$ transition and fine structure of Be-like systems. Phys. Rev. A 1989, 40, 4203-4208.

42. Hata, J.; Grant, I.P. The $1 \mathrm{~s} 2 \mathrm{~s} 2 \mathrm{p}^{2}{ }^{5} \mathrm{P}-1 \mathrm{~s} 2 \mathrm{p}^{3}{ }^{5} \mathrm{~S}$ transitions in the beryllium isoelectronic sequence. J. Phys. B At. Mol. Phys. 1983, 16, L125-L128. [CrossRef]

43. Chung, K.T.; Davis, B.F. Transition wavelength and fine structure for the quartet states of Be ${ }^{+}$. Phys. Rev. A 1984, 29, 1871-1877. [CrossRef]

44. Davis, B.F.; Chung, K.T. Transition wavelengths and fine structure for the doublet states of Be ${ }^{+}$. Phys. Rev. A 1984, 29, 2586-2590. [CrossRef]

45. Davis, B.F.; Chung, K.T. Spin-induced autoionization and radiative transition rates for the $(1 \mathrm{~s} 2 \mathrm{p} 2 \mathrm{p}){ }^{4} \mathrm{P}_{J}$ states in lithiumlike ions. Phys. Rev. A 1988, 37, 111-118. [CrossRef] [PubMed]

46. Davis, B.F.; Chung, K.T. Spin-induced autoionization and radiative transition rates for the (1s2s $2 \mathrm{p}){ }^{4} \mathrm{P}_{J}^{\mathrm{o}}$ states in lithiumlike ions. Phys. Rev. A 1989, 39, 3942-3955. [CrossRef] [PubMed]

47. Aspromallis, G.; Nicolaides, C.A.; Komninos, Y. Multichannel relativistic autoionisation of negative ions: The 1s2s2 $\mathrm{p}^{3}{ }^{6} \mathrm{~S}_{5 / 2}^{\mathrm{o}}$ metastable state of Be ${ }^{-}$. J. Phys. B At. Mol. Phys. 1985, 18, L545-L549. [CrossRef]

48. Blanke, J.H.; Fricke, B.; Heinemann, D.; Sepp, W.-D.; Thies, B.; Göbenli, T.; Heckmann, P.; Möller, G.; Träbert, E. Study of $3 \mathrm{~d} 4 \mathrm{f}$ and $3 \mathrm{~d} 5 \mathrm{f}$ quartet and doublet transitions of doubly excited three-electron ions. Z. Phys. D 1989, 13, 1-7. [CrossRef]

49. Blanke, J.H.; Fricke, B.; Sepp, W.-D.; Heckmann, P.H.; Möller, G.; Wagner, C. Transitions between quintet states of doubly excited four-electron ions: Experiment and MCDF theory along the isoelectronic sequence. Phys. Scr. 1990, 42, 522-529. [CrossRef]

50. Blanke, J.H.; Fricke, B.; Heinemann, D.; Heckmann, P.H.; Möller, G.; Träbert, E. Further investigations on doubly excited four-electron ions: Beam-foil experiment and MCDF theory. Phys. Scr. 1991, 44, $436-441$. [CrossRef]

51. Blanke, J.H.; Fricke, B.; Heckmann, P.H.; Träbert, E. First results of experimental and theoretical investigations on sextet states of doubly-excited five-electron ions. Phys. Scr. 1992, 45, 430-435. [CrossRef]

52. Chen. M.H.; Crasemann, B. Lifetime of the $1 \mathrm{~s} 2 \mathrm{p} 3 \mathrm{~d}{ }^{4} \mathrm{~F}_{9 / 2}$ metastable state of Li-like ions. Phys. Rev. A 1987, 35, 4839-4841. [CrossRef]

53. Désesquelles, J.; Buchet-Poulizac, M.C.; Bernard, J.; Brédy, R.; Chen, L.; Denis, A.; Martin, S.; Berry, H.G. Collision spectroscopy of normal and displaced terms for boronlike $\mathrm{O}^{3+}, \mathrm{F}^{4+}$ and $\mathrm{Ne}^{5+}$ ions. Phys. Scr. 2001, T92, 290-293.

54. Zouros, T.J.M.; Sulik, B.; Gulyás, L.; Orbán, A. Production of projectile 1s2s2p ${ }^{4} \mathrm{P}$ states by transfer-loss in collisions of $\mathrm{O}^{5+}$ and $\mathrm{F}^{6+}$ ions with $\mathrm{H}_{2}$ and He targets. J. Phys. B At. Mol. Opt. Phys. 2006, 39, L45-L52. [CrossRef]

55. Benis, E.P.; Zouros, T.J.M. Determination of the $1 \mathrm{~s} 2 \ell 2 \ell^{\prime}$ state production ratios ${ }^{4} \mathrm{P}^{\mathrm{o}} /{ }^{2} \mathrm{P},{ }^{2} \mathrm{D} /{ }^{2} \mathrm{P}$ and ${ }^{2} \mathrm{P}_{+} /{ }^{2} \mathrm{P}_{-}$ from fast $\left(1 \mathrm{~s}^{2}, 1 \mathrm{~s} 2 \mathrm{~s}^{3} \mathrm{~S}\right)$ mixed- state He-like ion beams in collisions with $\mathrm{H}_{2}$ targets. J. Phys. B At. Mol. Opt. Phys. 2016, 49, 235202. [CrossRef]

56. Miecznik, G.; Brage, T. J-dependent lifetimes of the $2 \mathrm{~s} 2 \mathrm{p} 3 \mathrm{p}{ }^{4} \mathrm{D}^{\mathrm{e}}$ and $2 \mathrm{~s} 2 \mathrm{p} 3 \mathrm{~d}{ }^{4}$ Fo terms in the boron isoelectronic sequence. J. Phys. B At. Mol. Opt. Phys. 1995, 28, 4233-4247. [CrossRef]

57. Johnson, B.M.; Jones, K.W.; Gregory, D.C.; Kruse, T.H., Träbert, E. Beam-foil lifetimes of $\mathrm{n}=3$ levels in Fe XIII to Fe XVI; I. Experiment using position sensitive detection. Phys. Lett. A 1981, 86, 285-288. [CrossRef] 
58. Träbert, E.; Suleiman, J.; Cheng, S.; Berry, H.G.; Dunford, R.W.; Kanter, E.W.; Kurtz, C.; Livingston, A.E.; Kukla, K.W.; Serpa, F.G.; et al. Experimental transition probabilities of intercombination transitions in Mg-like and Al-like ions of bromine. Phys. Rev. A 1993, 47, 3805-3809. [CrossRef]

59. Churilov, S.S.; Levashov, V.E. The $3 \mathrm{p}^{2} 3 \mathrm{~d}$ and $3 \mathrm{~s}_{3} \mathrm{~d}^{2}$ configurations in aluminium-like K VII-Ni XVI. Phys. Scr. 1993, 48, 425-435. [CrossRef]

60. Träbert, E., Wagner, C.; Heckmann, P.H.; Möller, G.; Brage, T. A beam-foil study of the $3 \mathrm{~s} 3$ p3d ${ }^{4} \mathrm{~F}$ levels in the Al-like ions of Ti, Fe and Ni. Phys. Scr. 1993, 48, 593-597.

61. Träbert, E.; Hoffmann, J.; Krantz, C.; Wolf, A.; Ishikawa, Y.; Santana, J.A. Atomic lifetime measurements on forbidden transitions of Al-, Si-, P- and S-like ions at a heavy-ion storage ring. J. Phys. B At. Mol. Opt. Phys. 2009, 42, 025002. [CrossRef]

62. Nemouchi, M.; Godefroid, M.R. Irreducible tensor form of the relativistic corrections to the M1 transition operator. L. Phys. B At. Mol. Opt. Phys. 2009, 42, 175002. [CrossRef]

63. Schneider, D.; Bruch, R.; Shlyaptseva, A.; Brage, T.; Ridder, D. Auger decay of Na-like Si ${ }^{3+}\left(2 \mathrm{p}^{5} 3 \ell 3 \ell^{\prime}\right)$ states formed in slow $\mathrm{Si}^{5+} \rightarrow \mathrm{He}$ and Ar ion atom collisions. Phys. Rev. A 1995, 51, 4652-4661. [CrossRef]

64. Jupén, C.; Engström, L.; Hutton, R.; Träbert, E. Identification of the core-excited $2 \mathrm{p}^{5} 3 \mathrm{~s} 3 \mathrm{p}^{4} \mathrm{D}_{7 / 2}-2 \mathrm{p}^{5} 3 \mathrm{~s} 3 \mathrm{~d}$ ${ }^{4} \mathrm{~F}_{9 / 2}$ transition in Na-like ions ranging from S VI to Cu XIX. J. Phys. B At. Mol. Phys 1988, 21, L347-L351. [CrossRef]

65. Jupén, C.; Engström, L.; Hutton, R.; Reistad, N.; Westerlind, M. Analysis of core-excited $n=3$ configurations in S VI, Cl VII, Ar VIII and Ti XII. Phys. Scr. 1990, 42, 44-50. [CrossRef]

66. Cowan, R.D. The Theory of Atomic Structure and Spectra; University of California Press: Berkeley, CA, USA, 1981.

67. Kramida, A. Cowan code: 50 years of growing impact on atomic physics. Atoms 2019, 7, 64. [CrossRef]

68. Chen, M.H. Effects of relativity and configuration interaction on L-shell Auger and radiative decays of the doubly excited $3 \ell 3 \ell^{\prime}$ states of sodiumlike ions. Phys. Rev. A 1989, 40, 2365-2372. [CrossRef]

69. Møller, C.; Plesset, M.S. Note on an approximation treatment for many-electron systems. Phys. Rev. 1934, 46, 618-622. [CrossRef]

70. Vilkas, M.J.; Ishikawa, Y. High-accuracy calculations of term energies and lifetimes of silicon-like ions with nuclear charges Z = 24-30. J. Phys. B At. Mol. Opt. Phys. 2004,37, 1803-1816. [CrossRef]

71. Vilkas, M.J.; Ishikawa, Y. Relativistic many-body perturbation calculations on extreme ultraviolet and soft-X-ray transition energies in siliconlike iron. Phys. Rev. A 2004, 69, 062503. [CrossRef]

72. Vilkas, M.J.; University of Puerto Rico, San Juan, Puerto Rico, USA; Ishikawa, Y.; University of Puerto Rico, San Juan, Puerto Rico, USA. Personal communication, 2005.

73. Delaunay, B. Heavy-ion stripping. Nucl. Instrum. Meth. 1977, 146, 101-113. [CrossRef]

74. Shima, K.; Kuno, N.; Yamanouchi, M.; Tawara, H. Equilibrium charge fractions of ions of Z = 4-92 emerging from a carbon foil. At. Data Nucl. Data Tab. 1992, 51, 173-241. [CrossRef]

75. Kramida, A.; Ralchenko, Yu.; Reader, J.; NIST ASD Team. NIST Atomic Spectra Database (Version 5.7); National Institute of Standards and Technology: Gaithersburg, MD, USA, 2019. Available online: https: / / physics.nist.gov/asd (accessed on 10 October 2019).

76. Kelly, R.L. Atomic and ionic spectrum lines below 2000 Angstroms. J. Phys. Chem. Ref. Data 1987, 16 (Suppl. 1), 1371-1678.

77. Del Zanna, G.; Dere, K.P.; Young, P.R.; Landi, E.,; Mason, H.E. CHIANTI-An atomic database for emission lines. Astron. Astrophys. 2015, 582, A56. [CrossRef]

78. Träbert, E.; Beiersdorfer, P.; Lepson, J.K.; Reinke, M.L.; Rice, J.E. EUV spectra and line ratios of multiply ionized calcium and argon atoms in a laboratory plasma. Astrophys. J. 2018, 865, 148. [CrossRef]

79. Beiersdorfer, P.; Lisse, C.M.; Olson, R.E.; Brown, G.V.; Chen, H. X-ray velocimetry of solar wind ion impact on comets. Astrophys. J. 2001, 549, L147-L150. [CrossRef]

80. Beiersdorfer, P.; Boyce, K.R.; Brown, G.V.; Chen, H.; Kahn, S.M.; Kelley, R.L.; May, M.; Olson, R.E.; Porter, F.S.; Stahle, C.K.; et al. Laboratory simulation of charge exchange-produced X-ray emission from comets. Science 2003, 300, 1558-1559. [CrossRef] [PubMed]

81. Beiersdorfer, P.; Schweikhard, L.; Liebisch, P.; Brown, G.V. X-ray signature of charge exchange in the spectra of L-shell iron ions. Astrophys. J. 2008, 672, 726-732. [CrossRef]

82. Frankel, M.; Beiersdorfer, P.; Brown, G.V.; Gu, M.F.; Kelley, R.L.; Kilbourne, C.A.; Porter, F.S. X-ray signature of charge exchange in L-shell sulfur ions. Astrophys. J. 2009, 702, 171-177. [CrossRef] 
83. Leutenegger, M. A.; Betancourt-Martinez, G.L.; Beiersdorfer, P.; Brown, G.V.; Kelley, R.L.; Kilbourne, C.A.; Porter, F.S. Charge exchange measurements with an X-ray calorimeter at an electron beam ion trap. Phys. Scr. 2013, T156, 014006. [CrossRef]

84. Träbert, E.; Beiersdorfer, P.; Pinnington, E.H.; Utter, S.B.; Vilkas, M. J.; Ishikawa, Y. Experiment and theory in interplay on high-Z few-electron ion spectra from foil-excited ion beams and electron beam ion traps. J. Phys. Conf. Ser. 2007, 58, 93-96.

85. Träbert, E. Extreme ultraviolet spectra of highly charged Fe ions in the laboratory versus the excitation of spectra in astrophysical environments. Can. J. Phys. 2017, 95, 777-782. [CrossRef]

86. Beiersdorfer, P.; Schweikhard, L.; Crespo López-Urrutia, J.; Widmann, K. The magnetic trapping mode of an electron beam ion trap: New opportunities for highly charged ion research. Rev. Sci. Instrum. 1996, 67, 3818-3826. [CrossRef]

(C) 2019 by the author. Licensee MDPI, Basel, Switzerland. This article is an open access article distributed under the terms and conditions of the Creative Commons Attribution (CC BY) license (http://creativecommons.org/licenses/by/4.0/). 